\title{
Relationship between microalbuminuria and cardiac structural changes in mild hypertensive patients
}
F.L. Plavnik,
M.A.M.R.T. Silva,
N.E.B. Kohlmann,
O. Kohlmann Jr.,
A.B. Ribeiro and
M.T. Zanella

Divisão de Nefrologia, Grupo de Hipertensão e Diabetes, Escola Paulista de Medicina, Universidade Federal de São Paulo, São Paulo, SP, Brasil

\section{Correspondence}

F.L. Plavnik

Divisão de Nefrologia

EPM, UNIFESP

Rua Borges Lagoa, 960

04038-002 São Paulo, SP

Brasil

Fax: +55-11-5579-2985

E-mail: fplavnik@zaz.com.br

Publication supported by FAPESP.

Received July 19, 2001

Accepted May 22, 2002

\section{Abstract}

The aim of this study was to determine the relationship between urinary albumin excretion (UAE), cardiac structural changes upon echocardiography and 24-h ambulatory blood pressure (ABPM) levels. Twenty mild hypertensive patients (mean age $56.8 \pm 9.6$ years) were evaluated. After 2 weeks of a washout period of all antihypertensive drugs, all patients underwent an echocardiographic evaluation, a 24-h ABPM and an overnight urine collection. Systolic and diastolic blood pressure during 24-h ABPM was $145 \pm 14 / 91 \pm 10 \mathrm{mmHg}$ (daytime) and $130 \pm 14 / 76 \pm 8 \mathrm{mmHg}$ (nighttime), respectively. Seven (35\%) patients presented $\mathrm{UAE} \geq 15 \mu \mathrm{g} / \mathrm{min}$, and for the whole group, the geometric mean value for UAE was $10.2 \mathrm{x} / \div 3.86 \mu \mathrm{g} / \mathrm{min}$. Cardiac measurements showed mean values of interventricular septum thickness (IVS) of $11 \pm 2.3 \mathrm{~mm}$, left ventricular posterior wall thickness (PWT) of $10 \pm 2.0 \mathrm{~mm}$, left ventricular mass (LVM) of $165 \pm 52 \mathrm{~g}$, and left ventricular mass index (LVMI) of $99 \pm 31 \mathrm{~g} / \mathrm{m}^{2}$. A forward stepwise regression model indicated that blood pressure levels did not influence UAE. Significant correlations were observed between UAE and cardiac structural parameters such as IVS $(r=0.71, \mathrm{P}<0.001)$, PWT $(r=0.64, \mathrm{P}<0.005)$, LVM $(r=0.65, \mathrm{P}<0.005)$ and LVMI $(\mathrm{r}=$ $0.57, \mathrm{P}<0.01)$. Compared with normoalbuminuric patients, those who had microalbuminuria presented higher values of all cardiac parameters measured. The predictive positive and negative values of UAE $\geq 15 \mu \mathrm{g} / \mathrm{min}$ for the presence of geometric cardiac abnormalities were 75 and $91.6 \%$. These data indicate that microalbuminuria in essential hypertension represents an early marker of cardiac structural damage.

\section{Introduction}

Several studies have demonstrated that 24-h ambulatory blood pressure monitoring (ABPM) is more closely related to target organ damage than casual measurements $(1,2)$. Cardiac structures assessed by echo-

\section{Key words}

- Hypertension

- Microalbuminuria

- Left ventricular hypertrophy

- Blood pressure monitoring 
abnormalities in target organs of hypertension such as retinopathy (4) and urinary albumin excretion (UAE) have shown a correlation with ABPM (5).

Increased UAE has been reported to be a strong predictor of cardiovascular events in hypertensive patients. The importance of this finding is not completely clear but it seems that there is an association between UAE and the other cardiovascular risk factors such as obesity, insulin resistance, impaired lipid profile and blood pressure (6-8).

The prevalence of microalbuminuria in untreated hypertensive patients ranges from 20 to $40 \%$ according to the method used (911). In some studies patients treated with diuretics or beta-blockers showed a prevalence of $25 \%$, while others have described a prevalence of proteinuria in a range of 4 to $16 \%(12,13)$. The degree of microalbuminuria was positively correlated with office blood pressure although better correlations have been observed using 24-h ambulatory monitoring. Also, a negative correlation has been detected between UAE and the nocturnal blood pressure fall (14-16). Some clinical studies have shown not only a positive correlation between blood pressure levels and microalbuminuria, but also a positive correlation between microalbuminuria and other target organs of hypertensive disease such as LVM and retinopathy $(17,18)$.

Increased UAE by essential hypertensive patients has been interpreted to be a marker of early intrarenal vascular endothelial dysfunction (19). It may be also a risk factor for renal function deterioration (20). The aim of the present study was to determine the relationship between microalbuminuria, cardiac structural changes and blood pressure levels determined by 24 -h ambulatory monitoring, in mild hypertensive patients.

\section{Patients and Methods}

Patients of both sexes considered to be mild hypertensives (defined as patients with blood pressure levels below $159 \mathrm{mmHg}$ for systolic pressure and $99 \mathrm{mmHg}$ for diastolic pressure after 2 weeks of withdrawal of their antihypertensive medication and no evidence of target organ damage) were eligible for inclusion. They were seen regularly at 3-month intervals at the Hypertension and Diabetes Outpatient Clinic, Hospital do Rim e Hipertensão. Patients with abnormal fasting glucose $(\geq 126 \mathrm{mg} / \mathrm{dl})$ and serum creatinine levels $(>1.2 \mathrm{mg} / \mathrm{dl})$, as well as those with abnormalities upon echocardiogram evaluation or heart disease were not included. A total of 20 patients $(6 \mathrm{men} / 14$ women aged $42-70$ years) were evaluated. The time since the diagnosis of hypertension ranged from 1 to 47 years (mean of $13.7 \pm 10.2$ years).

None of the participants had any clinical hypertensive complications. The local Ethics Committee (UNIFESP) approved this protocol which conformed to the guidelines of the Declaration of Helsinki and informed consent was obtained from the subjects.

\section{Blood pressure determinations}

Office blood pressure. Blood pressure levels were determined after at least $5 \mathrm{~min}$ of rest in the sitting position using a mercury sphygmomanometer. The same physician performed all measurements and a mean of three determinations was used. Systolic and diastolic blood pressure corresponded to phases I and V of the Korotkoff sound, respectively.

Blood pressure monitoring. ABPM was performed using a noninvasive automatic monitor (SpaceLabs, model 90207). We considered the period during which subjects carried out their normal activities as daytime and nighttime as the period of sleeping. Blood pressure was measured every $15 \mathrm{~min}$ during the daytime and every $20 \mathrm{~min}$ during the nighttime. The data for subjects with less than $80 \%$ of valid measurements were excluded from analysis. The measurements of the mean systolic and diastolic blood pres- 
sure obtained from this evaluation were used in the subsequent analysis. All participants were asked to perform their normal daily activities.

Echocardiography. Cardiac structures were evaluated with an M-mode and twodimensional echocardiographic Esaote Biomedica apparatus (Florence, Italy), model SIM 5000, equipped with a $2.5-\mathrm{MHz}$ mechanical transducer. Patients lay in left decubitus with a slight rotation of the chest. The echocardiographic parameters evaluated were PWT, IVS, both measured at diastole, and LVM calculated according to the American Society of Echocardiography (21).

LVMI was obtained by dividing LMV by body surface area and was considered normal when the values were below $110 \mathrm{~g} / \mathrm{m}^{2}$ for women and $134 \mathrm{~g} / \mathrm{m}^{2}$ for men.

Relative IVS (RIVS) and relative PWT (RPWT) were calculated from the following expressions:

$$
\operatorname{RIVS}=2 \times \operatorname{IVS}(\mathrm{mm}) / \operatorname{LVEDD}(\mathrm{mm})
$$

$$
\text { RPWT }=2 \times \text { PWT }(\mathrm{mm}) / \text { LVEDD }(\mathrm{mm})
$$

where LVEDD = left ventricle end-diastolic diameter.

Laboratory parameters. All patients had an overnight $(12 \mathrm{~h})$ urine sample collected for UAE measurement, using an immunoturbidimetric method with a specific antibody automatized by CobasMira Plus, Roche (Basel, Switzerland).

\section{Statistical analysis}

Data were analyzed with the SigmaStat for Windows software, version 1.0 (Jandel Corporation, Chicago, IL, USA). Data are reported as mean $\pm \mathrm{SD}$ or median and its confidence intervals. Forward stepwise regression analysis was used to identify the variables that could be predictors or determinants of microalbuminuria and cardiac structural changes. The correlation between car- diac and renal variables was determined by Spearman correlation. For further analysis, microalbuminuria values were log transformed to correct the skewing in distribution. The association between microalbuminuria and increased values of cardiac parameters was tested by Fisher's exact test. Differences were considered significant at $\mathrm{P}<0.05$.

\section{Results}

Table 1 shows the clinical characteristics of the subjects. Blood pressure levels obtained with 24-h ABPM showed a mean for systolic and diastolic pressure of $145 \pm 14$ / $91 \pm 10 \mathrm{mmHg}$ (vigil) and $130 \pm 14 / 76 \pm 8$ $\mathrm{mmHg}$ (sleep), respectively, and the median blood pressure fall during sleep was $10.5 \%$ (5.2-17.1).

Cardiac evaluation showed that 8 patients (40\%), 3 men and 5 women, had both IVS and PWT above the normal range and 4 (20.0\%), one man and 3 women, had left ventricular hypertrophy when adjusted for sex. The mean values of these parameters for the remaining subjects were within the normal range: IVS - $11 \pm 2.3 \mathrm{~mm}$, PWT $-10 \pm$ $2.0 \mathrm{~mm}, \mathrm{LVM}-165 \pm 52 \mathrm{~g}$ and LVMI $-99 \pm$ $31 \mathrm{~g} / \mathrm{m}^{2}$.

Urinary albumin excretion greater than $15 \mu \mathrm{g} / \mathrm{min}$ (defined as microalbuminuria)

\begin{tabular}{|c|c|c|c|}
\hline Characteristics & $\begin{array}{l}\text { All subjects } \\
\qquad(\mathrm{N}=20)\end{array}$ & $\begin{array}{c}N A \\
(N=13)\end{array}$ & $\begin{array}{c}\text { MA } \\
(N=7)\end{array}$ \\
\hline Age (years) & $56.8 \pm 9.6$ & $55.0 \pm 10.3$ & $60.0 \pm 7.0$ \\
\hline Duration of hypertension (years) & $13.7 \pm 10.2$ & $14.2 \pm 11.8$ & $12.6 \pm 6.8$ \\
\hline Body mass index $\left(\mathrm{kg} / \mathrm{m}^{2}\right)$ & $27.7 \pm 4.1$ & $27.2 \pm 11.8$ & $28.8 \pm 2.6$ \\
\hline Office systolic blood pressure $(\mathrm{mmHg})$ & $147.0 \pm 11.7$ & $146.3 \pm 17.2$ & $147.9 \pm 16.3$ \\
\hline Office diastolic blood pressure $(\mathrm{mmHg})$ & $87.0 \pm 7.0$ & $86.4 \pm 6.7$ & $87.1 \pm 7.6$ \\
\hline Serum glucose (mg/dl) & $86.8 \pm 14.2$ & $86.3 \pm 12.7$ & $86.7 \pm 16.8$ \\
\hline UAE ( $\mu \mathrm{g} / \mathrm{min})$ & $10.2 \times / \div 3.86$ & $4.53 \times / \div 1.68$ & $44.3 \times / \div 2.61$ \\
\hline
\end{tabular}
was found in $7(35 \%)$ patients and the geo-

Data are reported as means \pm SD. Data for urinary albumin excretion (UAE) are reported as geometric mean and SD. 

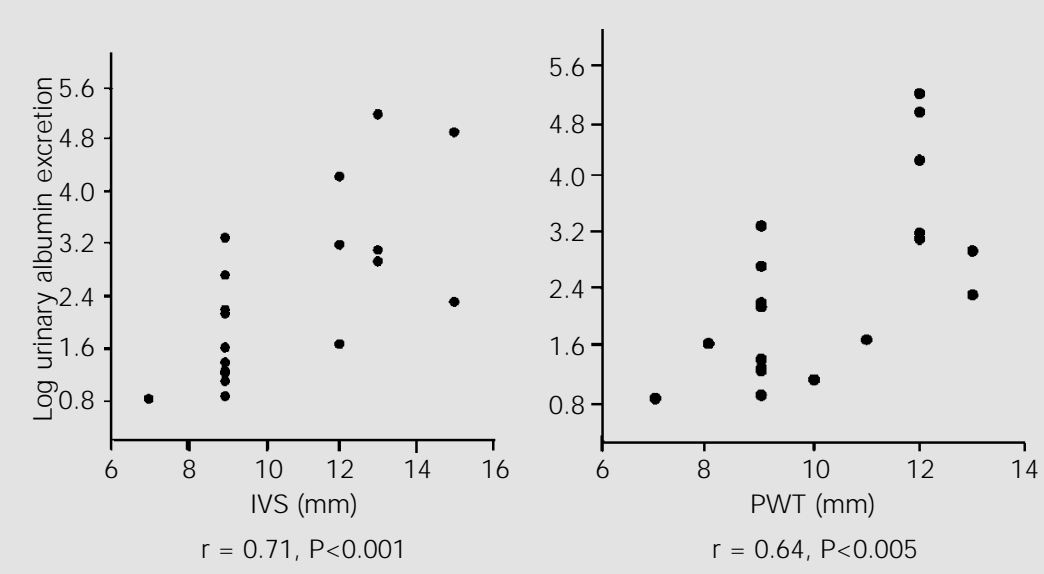

Figure 1. Correlations of microalbuminuria with interventricular septum thickness (IVS) and with left ventricular posterior wall thickness (PWT) for 20 patients.

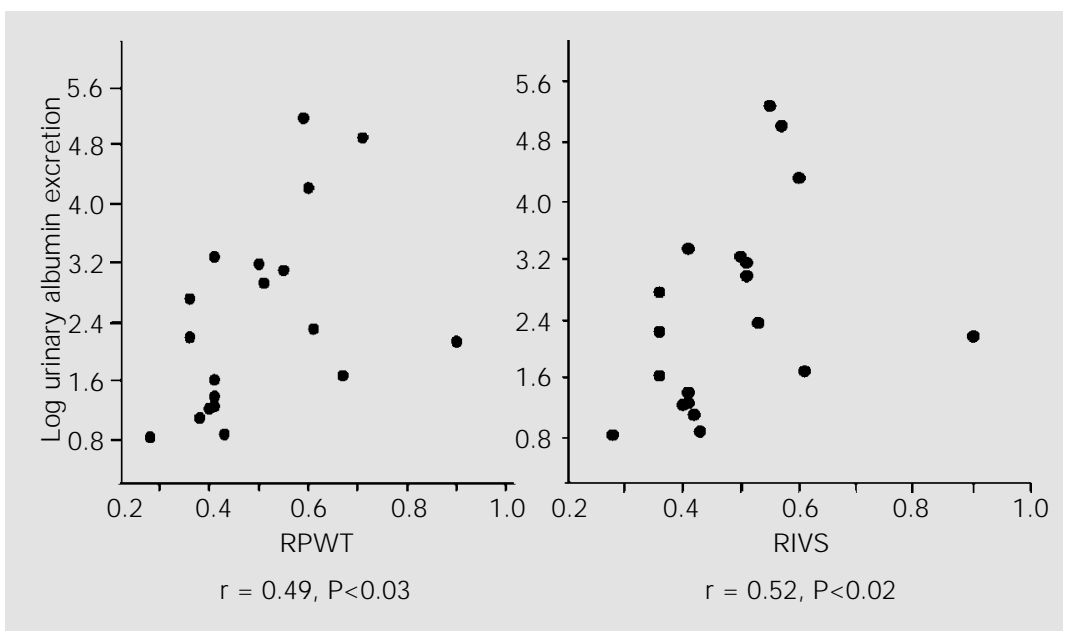

Figure 2. Correlations of microalbuminuria with relative left ventricular wall thickness (RPWT) and with relative interventricular septum thickness (RIVS) for 20 patients.

Table 2. Blood pressure obtained by 24-h ambulatory blood pressure monitoring of the NA and MA patients.

\begin{tabular}{lccc}
\hline Blood pressure $(\mathrm{mmHg})$ & $\begin{array}{c}\text { All patients } \\
(\mathrm{N}=20)\end{array}$ & $\begin{array}{c}\mathrm{NA} \\
(\mathrm{N}=13)\end{array}$ & $\begin{array}{c}\mathrm{MA} \\
(\mathrm{N}=7)\end{array}$ \\
\hline Vigil & & & \\
$\quad$ SBP & $145 \pm 14$ & $143 \pm 11$ & $150 \pm 19.7$ \\
DBP & $91 \pm 10$ & $88.9 \pm 9.5$ & $95.2 \pm 10.2$ \\
Sleep & & & \\
$\quad$ SBP & $130 \pm 14$ & $130 \pm 13.8$ & $130 \pm 16.2$ \\
DBP & $76 \pm 8.0$ & $74.8 \pm 8.6$ & $77.2 \pm 7.3$ \\
Nocturnal fall (\%) & $10.6 \pm 6.5$ & $9.4 \pm 6.9$ & $13.2 \pm 5.0$ \\
\hline
\end{tabular}

Data are reported as means \pm SD. NA, normoalbuminuric patients; MA, microalbuminuric patients; SBP, systolic blood pressure; DBP, diastolic blood pressure. metric mean value was $10.2 \mathrm{x} / \div 3.86 \mu \mathrm{g} /$ min, ranging from 1.5 to $173 \mu \mathrm{g} / \mathrm{min}$.

When a stepwise regression model was applied, no ABPM values (mean 24-h, vigil and night), age, BMI or duration of hypertension showed any influence on UAE. When the same model was applied to cardiac structures only LVMI was influenced by the time of diagnosis of hypertension and sleeptime diastolic blood pressure $\left(\mathrm{r}^{2}=0.60, \mathrm{P}<0.05\right)$. The duration of the hypertensive process could explain $44 \%$ of the increases observed in LVMI and the nighttime diastolic blood pressure levels could explain $16 \%$.

The Spearman test indicated a positive and significant correlation between UAE and cardiac measurements such as absolute IVS $(\mathrm{r}=0.71, \mathrm{P}<0.001)$ and PWT $(\mathrm{r}=0.64$, $\mathrm{P}<0.005$ ) (Figure 1), as well as between UAE and relative IVS $(\mathrm{r}=0.52, \mathrm{P}<0.02)$ and PWT $(r=0.49, \mathrm{P}<0.03)$ (Figure 2). Urinary albumin excretion was also correlated with LVM $(\mathrm{r}=0.65, \mathrm{P}<0.005)$ and LVMI $(\mathrm{r}=$ $0.57, \mathrm{P}<0.01)$.

A comparison between normoalbuminuric $(\mathrm{N}=13)$ and microalbuminuric $(\mathrm{N}=7)$ patients showed no differences regarding age, BMI, duration of hypertension or blood pressure values determined during ABPM (Table 2). In contrast, the cardiac parameters indicated statistically significant differences between groups (Table 3 ).

Microalbuminuria (UAE $>15 \mu \mathrm{g} / \mathrm{min}$ ) showed a positive predictive value of $75 \%$ and a negative predictive value of $91.6 \%$ (Table 4) for geometric cardiac abnormalities.

\section{Discussion}

Microalbuminuria has been considered to be a marker of cardiovascular risk in diabetic $(22,23)$ and non-diabetic subjects (6). The importance of increased UAE levels in essential hypertension is unclear. However, increased UAE has been related not only to blood pressure levels (24) and left ventricular hypertrophy (17) but also to sev- 
eral other risk factors such as hyperinsulinemia, dislipidemia and obesity, which comprise a cluster of metabolic abnormalities $(8,15,25,26)$.

In the present study, UAE was not explained by any of the variables included in a regression model, such as age, duration of hypertension, or BMI. These findings are consistent with the data reported by Palatini et al. (26). In contrast to some reports $(20,27)$, our results did not show any correlation between UAE and blood pressure. This suggests that UAE is not directly dependent on blood pressure levels but depends on renal vascular damage secondary to the hypertensive process.

The association between UAE levels and LVMI demonstrated in our patients has also been reported in untreated hypertensives and in patients with white coat hypertension $(28,29)$. In our study, correlations were also detected between absolute or relative IVS and PWT values and UAE. These findings indicate that UAE is associated with concentric cardiac remodeling, the structural change that precedes the development of left ventricular hypertrophy. This finding supports data reported by Pontremoli et al. (30) who also reported a higher prevalence of unfavorable left ventricular geometric patterns in microalbuminuric patients. The comparison between normoalbuminuric and microalbuminuric subjects confirms our hypothesis that microalbuminuria is a marker of early cardiac changes, as previously suggested in the literature (31). As shown by Bulatov et al. (32), there is a continuous relationship between albumin excretion rate, LVM assessed by echocardiography, and ambulatory blood pressure in newly diagnosed patients with essential hypertension. This suggests that the early effects of blood pressure on target organs such as kidneys and heart occur in parallel (32). The presence of microalbuminuria has been understood to be a renal manifestation of generalized increased endothelial dysfunction.

Our data agree with observations sug-
Table 3. Cardiac structure measurements of normoalbuminuric (NA) and microalbuminuric (MA) patients.

\begin{tabular}{lccc}
\hline Cardiac structures & NA & MA & P \\
\hline IVS $(\mathrm{mm})$ & $9.6 \pm 2.0$ & $12.4 \pm 1.8$ & 0.007 \\
PWT $(\mathrm{mm})$ & $9.3 \pm 1.5$ & $11.7 \pm 1.3$ & 0.0025 \\
LVM $(\mathrm{g})$ & $144 \pm 47$ & $203 \pm 45$ & 0.016 \\
LVMI $\left(\mathrm{g} / \mathrm{m}^{2}\right)$ & $80(74.5-93)$ & $114(107-128.5)$ & 0.009 \\
RIVS & $0.41(0.36-0.48)$ & $0.51(0.50-0.57)$ & $\mathrm{NS}$ \\
RPWT & $0.41(0.37-0.52)$ & $0.55(0.50-0.60)$ & $\mathrm{NS}$ \\
\hline
\end{tabular}

Data are reported as means \pm SD or medians (95\% confidence intervals). IVS, interventricular septum thickness; PWT, left ventricular posterior wall thickness; LVM, left ventricular mass; LVMI, left ventricular mass index; RIVS, relative interventricular septum thickness; RPWT, relative posterior wall thickness; NS, not significant. The two patient groups were compared by the Student t-test or Wilcoxon test for median and $\mathrm{Cl}$.

Table 4. Predictive value of urinary albumin excretion (UAE) regarding cardiac structural changes (CSC).

\begin{tabular}{lcc}
\hline & $\begin{array}{c}\text { UAE } \\
>15 \mu \mathrm{g} / \mathrm{min} \\
(\mathrm{N}=7)\end{array}$ & $\begin{array}{c}\text { UAE } \\
\leq 15 \mu \mathrm{g} / \mathrm{min} \\
(\mathrm{N}=13)\end{array}$ \\
\hline Presence of CSC & 6 & 2 \\
Absence of CSC & 1 & 11
\end{tabular}

gesting that determination of UAE is useful for the identification of a subset of patients who could be more prone to developing left ventricular hypertrophy, contributing to the stratification of cardiovascular risk in hypertensive patients $(25,27,33,34)$.

The presence of increased UAE levels in mild hypertension and its association with cardiac structure abnormalities may be considered to be not only evidence of early renal vascular damage, but also as a marker of geometric cardiac changes.

Taking into account the positive predictive value found in this study, the presence of microalbuminuria in hypertensive subjects seems to be a very important test to be considered in the evaluation of cardiovascular risk in this population. 


\section{References}

1. Perloff D, Sokolow M \& Cowan R (1983). The prognostic value of ambulatory blood pressure. J oumal of the American Medical Association, 249: 2792-2798.

2. White WB (1991). Relationship among casual and ambulatory blood pressure and target organ involvement in essential hypertension. Clinical and Investigative Medicine, 14: 224-230.

3. Rowlands DB, Ireland MA, Glover DR, McLeay RAB, Stallard TJ \& Littler WA (1981). The relationship between ambulatory blood pressure and echocardiographically assessed left ventricular hypertrophy. Clinical Science, 61 (Suppl 7): 101S-103S.

4. Perloff D \& Sokolow M (1990). Ambulatory blood pressure: the San Francisco experience. J ournal of Hypertension, 8 (Suppl 6): S105-S111.

5. Veerman DP, de Blok $K \&$ van Montfrans GA (1996). Relationship of steady state and ambulatory blood pressure variability to left ventricular mass and urinary albumin excretion in essential hypertension. American J ourmal of Hypertension, 9: 455460.

6. Yudkin J S, Forrest RD \& J ackson CA (1988). Microalbuminuria as a predictor of vascular disease in non-diabetic subjects. Islington Diabetes Survey. Lancet, ii: 530533.

7. Ferranini E (1993). The metabolic syndrome. In: Mogensen CE (Editor), Target Organ Damage in the Mature Hypertensive. Part 2. Science Press Ltd., London, England, 31-49.

8. Mogensen CE (1994). Systemic blood pressure and glomerular leakage with particular reference to diabetes and hypertension. J ournal of Internal Medicine, 235: 297-316.

9. Ljungman S (1990). Microalbuminuria in essential hypertension. American J ournal of Hypertension, 3: 956-960.

10. Bigazzi R, Bianchi S, Campese V \& Baldari $G$ (1992). Prevalence of microalbuminuria in a large population of patients with mild to moderate essential hypertension. Nephron, 152: 373-377.

11. Perera GA (1995). Hypertensive vascular disease: description and natural history. J ournal of Chronic Diseases, 1: 33-42.

12. Ruilope LM, Alcazar J M \& Rodicio J L (1992). Renal consequences of arterial hypertension. J ournal of Hypertension, 10 (Suppl 7): S85-S90.

13. Samuelsson O (1985). Hypertension in middle-aged man: management, morbidity and prognostic factors during longterm hypertensive care. Acta Medica Scandinavica, 702 (Suppl): 1-79.

14. Bianchi S, Bigazzi R, Baldari G, Sgherri G \& Campese VM (1994). Diurnal variations of blood pressure and microalbuminuria in essential hypertension. American J ournal of Hypertension, 7: 23-29.

15. Redon J, Liao Y, Lozano J V, Miralles A, Pascual J M \& Cooper RS (1994). Ambulatory blood pressure and microalbuminuria in essential hypertension: role of circadian variability. J ournal of Hypertension, 12: 947-953.

16. Giaconi S, Levanti C, Fommei E, Innocenti F, Seghieri G, Palla L, Palombo C \& Ghione $S$ (1989). Microalbuminuria and casual and ambulatory blood pressure monitoring in normotensives and in patients with borderline and mild essential hypertension. American J oumal of Hypertension, 2: 259261.

17. Redon J, Gomez-Sanchez MA, Baldo E, Casal MC, Fernandez ML, Miralles A, Gomez-Pajuelo C, Rodicio J L \& Ruilope LM (1991). Microalbuminuria is correlated with left ventricular hypertrophy in male hypertensive patients. J oumal of Hypertension, 9 (Suppl 6): S148-S149.

18. Biesenbach G \& Zazgomik J (1994). High prevalence of hypertensive retinopathy and coronary heart disease in hypertensive patients with persistent microalbuminuria under short intensive antihypertensive therapy. Clinical Nephrology, 41: 211-218.

19. Minram A, Ribstein J \& DuCalair G (1994). Is microalbuminuria a marker of early intrarenal vascular dysfunction in essential hypertension? Hypertension, 23 (Part 2): 1018-1021.

20. Cerasola G, Cottone S, Mulé G, Nardi E, Mangano MT, Andronico G, Contorno A, Li Vecchi M, Galione P, Renda F, Piazza G, Volpe V, Lisi A, Ferrara L, Panepinto N \& Riccobene R (1996). Microalbuminuria, renal dysfunction and cardiovascular complication in essential hypertension. J ournal of Hypertension, 14: 915-920.

21. Sahn DJ, DeMaria A, Kisslo J \& Weyman A (1978). The Committee on M-mode Standardization of the American Society of Echocardiography. Recommendations regarding quantitation in $\mathrm{M}$-mode echocardiography: results of a survey of echocardiographic measurements. Circulation, 58: 1072-1083.

22. Mogensen CE (1984). Microalbuminuria predicts clinical proteinuria and early mortality in maturity onset diabetes. New England J oumal of Medicine, 310: 356-360.

23. Deckert T, Koford-Enevoldsen A, Norgaard K, Borch-J ohnsen K, FeldtRassmussen B \& J ensen T (1992). Microalbuminuria. Implications for micro- and macrovascular disease. Diabetes Care, 15: 1181-1191.

24. Parving $\mathrm{HH}$, J ensen $\mathrm{H}$, Mogensen $\mathrm{CE} \&$
Envin PE (1974). Increased urinary albumin excretion rate in benign essential hypertension. Lancet, i: 1190-1192.

25. Redon J , Miralles A, Pascual J M, Baldó E, Robles RG \& Carmena R (1997). Hyperinsulinemia as a determinant of microalbuminuria in essential hypertension. J oumal of Hypertension, 15: 79-86.

26. Palatini $P$, Graniero GR, Canali $C$, Santonastaso $M$, Mos L, Piccolo D, D'Este $D$, Berton G, Zanata G \& De Venuto G (1995). Relationship between albumin excretion rate, ambulatory blood pressure and left ventricular hypertrophy in mild hypertension. J ournal of Hypertension, 13: 17961800.

27. Pontremoli $R$, Nicolella $C$, Viazzi $F$, Ravera M, Sofia A, Berruti V, Bezante GP, Del Sette M, Martinoli C, Sacchi G \& Deferrari $G$ (1998). Microalbuminuria is an early marker of target organ damage in essential hypertension. American J ournal of Hypertension, 11 (Part 1): 430-438.

28. Palatini $P$, Mormino $P$, Santonastaso $M$, Mos L, Dal Follo M, Zanata G \& Pessina AC (1998). Target-organ damage in stage I hypertensive subjects with white coat and sustained hypertension. Results from the HARVEST study. Hypertension, 31 (Part 1): 57-63.

29. Cerasola G, Cottone S, D'Ignoto G \& Grasso L (1992). Microalbuminuria points out early renal and cardiovascular changes in essential hypertension. Revista Latina de Cardiologia, 13: 3-7.

30. Pontremoli R, Ravera M, Bezante GP, Viazzi F, Nicolella C, Berruti V, Leoncini G, Del Sette M, Brunelli C, Tomolillo $C \&$ Deferrari G (1999). Left ventricular geometry and function in patients with essential hypertension and microalbuminuria. J ournal of Hypertension, 17: 993-1000.

31. Brakris GL (2001). Microalbuminuria: what is it? Why is it important? What should be done about it? J oumal of Clinical Hypertension, 3: 99-102.

32. Bulatov VA, Stenehjem A \& Os I (2001). Left ventricular mass assessed by electrocardiography and albumin excretion rate as a continuum in untreated essential hypertension. J ournal of Hypertension, 19: 1473-1478.

33. J anssen WMT, de J ong PE \& de Zeeuw D (1996). Hypertension and renal disease: role of microalbuminuria. J oumal of Hypertension, 14 (Suppl 5): S173-S177.

34. Post WS, Blumenthal RS, Weiss J L, Levine DM, Thiemann DR, Gerstenblith G $\&$ Hill MN (2000). Spot urinary albumincreatinine ratio predicts left ventricular hypertrophy in young hypertensive AfricanAmerican men. American J ournal of Hypertension, 13: 1168-1172. 